\title{
Responses of Leaf Celery to Floating Culture System with Different Depths of Water-substrate Interface and NPK-fertilizer Application
}

\author{
Karla Kasihta JAYA ${ }^{1}$, Benyamin LAKITAN ${ }^{1,2, *}$ and Siti Masreah BERNAS ${ }^{1}$ \\ ${ }^{1}$ College of Agriculture, Universitas Sriwijaya, Inderalaya 30662, Indonesia \\ ${ }^{2}$ Research Center for Sub-optimal Lands, Universitas Sriwijaya, Palembang 30139, Indonesia
}

('Corresponding author's e-mail: blakitan60@unsri.ac.id)

Received: 5 April 2021, Revised: 21 April 2021, Accepted: 1 May 2021

\begin{abstract}
Wetland areas in Indonesia cover more than 33,3 million hectares, and slightly less than $40 \%$ is inland swamp. During the rainy season, for up to 9 months annually, the wetlands are flooded, and no conventional agricultural activities can be done by local farmers. However, this condition can be seen as an opportunity to employ floating culture system. The objective of this research was to evaluate responses of leaf celery to floating culture system with different depths of water-substrate interface and NPKfertilizer application. The results of this study indicated that the depth of water-substrate interface (WSI) should be maintained between 1 to $3 \mathrm{~cm}$. At less than $1 \mathrm{~cm}$, continuous contact between the water surface and the bottom part of the substrate cannot be ensured; meanwhile, aerobic substrate volume was reduced and caused significant effects on growth and yield in celery plants if WSI was deeper than $3 \mathrm{~cm}$. Moreover, the effectiveness of NPK-fertilizer application was weakened if the depth of WSI was at $6 \mathrm{~cm}$. Fresh leaf yield in celery plants harvested at 45 days after transplanting (DAT) can be predicted as early as 3 weeks earlier using the midrib length of the largest leaf or plant height as a predictor measured at 26 DAT.
\end{abstract}

Keywords: Apium graveolens, Floating culture, Water-substrate interface, Wetlands, Yield prediction

\section{Introduction}

Leaf celery (Apium graveolens L. var. secalinum) is more popular in Asia, and has a smaller petiole, but produces more leaves compared to stalk celery (A. graveolens L. var. dulce) as is commonly consumed in western countries. Celery is rich in phenolic and antioxidant compounds [1] and has been consumed for medicinal purposes, to prevent, or lower the risk of, several diseases [2]. Leaf celery is an annual or biennial vegetable with leaves as a common part for consumption [3]. Leaf celery can be harvested frequently throughout its life cycle by plucking mature leaves from the stem. Yommi et al. [4] estimated that a mature celery plant could have approximately 20 compound leaves attached to the stem. Each compound leaf consists of 5 to 9 leaflets. Its petiole has collenchyma tissue comprised of elongated cells, with a thickening wall which provides strong but elastic structural support [5] and accommodates excessive water absorbed by roots [6].

The original native habitat of wild celery was in marsh land [7]. Therefore, leaf celery is expected to be suitable for cultivation in wetland ecosystems or by using floating culture system. Floating culture is traditionally practiced by local farmers for rice seedling preparation in tropical riparian wetland using local biomaterials for constructing floating rafts [8]. The floating culture was designed for adapting to flood-prone areas [9]. Further, floating culture system is also applied for vegetable production. Successful vegetable production using the floating system has been reported in green apple eggplant [10], chili pepper [11], and water spinach [12]. 
Celery cultivation using bottom wet culture has been successfully performed [13]. However, cultivation of leaf celery using floating culture system has not been intensively studied. Celery can be grown directly using seeds but also using young suckers collected from the mother plant. Celery seed is very tiny, has a low germination percentage, and takes time to germinate [14]. Early seed germination contributes to seedling performance and plant establishment in agricultural practice [15]. Therefore, leaf celery seedlings collected from suckers of 6-month-old leaf celery mother plants were used as planting material in this study, to shorten the production cycle and to bypass germination inconveniency. Different rates of NPK fertilizer were applied at 1 week after seedlings were transplanted, in order to evaluate response of celery to NPK application at early growth stage.

The objective of this study was to evaluate responses of leaf celery to floating culture system with different depths of water-substrate interface and NPK-fertilizer application.

\section{Materials and methods}

\section{Climate and plant material}

The study was carried out during the rainy season in tropical lowland climate at an outdoor research facility in Jakabaring ( $104^{\circ} 46^{\prime} 44^{\prime}$ ' E; $3^{\circ} 01^{\prime} 35^{\prime}$ ' S), Palembang, South Sumatra, Indonesia. The leaf celery (A. graveolens var. secalinum) seedlings used in this study were relatively homogenous in size (height and canopy diameter) and had 4 leaves. The seedlings were selected from suckers of 6-month-old leaf celery plants.

\section{Experiment setup}

Seedlings were transplanted to plastic pots filled with soil and manure mix $(3: 1 \mathrm{v} / \mathrm{v})$ to a height of $20 \mathrm{~cm}$. The dimensions of the plastic pots used were $30 \mathrm{~cm}$ in upper diameter, $20 \mathrm{~cm}$ in base diameter, and $25 \mathrm{~cm}$ in height. Pots used were customized to have 4 bottom holes which enabled direct contact between growing substrate and water at the base of the pot and 4 side holes at the height of $20 \mathrm{~cm}$ from the pot base to avoid waterlogging above substrate surface during heavy rain.

Floating cultivation system was performed in an experimental pool using 3 cultivation rafts. The raft dimensions were $2.0 \mathrm{~m}$ (length) $\times 1.0 \mathrm{~m}$ (width) $\times 0.078 \mathrm{~m}$ (height). Sixty-nine emptied plastic bottles (polyethylene terephthalate, PET) were used as floaters. Captive air within each bottle was $1,500 \mathrm{~cm}^{3}$. Polyvinyl chloride (PVC) pipes were used in constructing the designed frame of the raft. The floating raft received Indonesia granted patent no. IDP000065141 [16].

After seedlings were planted in soil-manure mix substrate in each pot, 18 pots were placed on each raft. Water-substrate interface (WSI) was managed by adding necessary extra weight on the raft until the upper raft surface was immersed at 1,3 , or $6 \mathrm{~cm}$ below the water surface, depending on the WSI treatment. Substrate moisture was measured at 1 and $5 \mathrm{~cm}$ depth. Measurement at $1 \mathrm{~cm}$ was for sensing the evaporation rate; meanwhile, measurement at $5 \mathrm{~cm}$ was for detecting whether upward water movement due to capillarity had reached to the substrate depth where root distribution was at the highest density.

\section{Experimental design}

This experiment was arranged based on a split plot design with 2 factors (main plot and sub-plot). Water-substrate interface (WSI) treatment was used as the main plot and NPK $(16: 16: 16 \mathrm{w} / \mathrm{w} / \mathrm{w})$ fertilizer rate application (F) as the sub-plot. The thickness of WSI treatments was $1 \mathrm{~cm}$ (WSI1), $3 \mathrm{~cm}$ (WSI3), and $6 \mathrm{~cm}$ (WSI6). Extra load was added to adjust each WSI treatment. F treatments applied at one week after transplanting (WAT) consisted of $15 \mathrm{~g} /$ pot (F15), $10 \mathrm{~g} /$ pot (F10), and $5 \mathrm{~g} /$ pot (F5). Each combination of $\mathrm{WSI} \times \mathrm{F}$ treatments consisted of 5 replications.

\section{Data collection}

Plant height, number of leaves, midrib length, and leaf width were measured regularly during preharvest period at 14, 18, 22, and 26 days after transplanting (DAT) as indicators of plant growth. Plant height was determined by measuring from petiole base to tip of terminal leaflet. The number of leaves 
was counted on the fully expanded leaves. Soil moisture was measured using a soil moisture meter (Lutron PMS-714) at depths of 1 and $5 \mathrm{~cm}$ below soil surface at 26 DAT. The number of harvested leaves, yield fresh weight, and shoot dry weight was measured at 26, 31, 38, and 45 DAT. The weight of plant materials was measured using a standard digital scale. Shoot dry weight was determined after samples were dried at $70{ }^{\circ} \mathrm{C}$ until a constant weight was obtained.

\section{Data analysis}

All data were organized and analyzed using the statistical analysis software (SAS 9.0 for Windows, SAS Institute Inc., Cary, North Carolina, US). Analysis of variance was used for evaluating significance of individual treatments and their interactions. Least significant difference test was carried out to access the significant difference in all sets of collected data. $\mathrm{P}<0.05$ was used to indicate statistical significance.

\section{Results and discussion}

Water availability within rhizosphere and water loss at upper surface

Substrate moistures measured at depths of 1 and $5 \mathrm{~cm}$ were significantly different in all thicknesses of water-substrate interface treatments (Figure 1). In floating culture system, the moisture is much lower near the substrate surface due to evaporation activity and capillarity action. Sunlight absorbed at the substrate surface increases substrate temperature, triggers evaporation activity, and in turn decreases substrate moisture. A long-term study had confirmed that temperature influenced soil moisture values [17]. Higher moisture content at deeper position in the substrate was associated with less water loss due to evaporation and continuous upward water supply from the lower part of the substrate in direct contact with water surface due to capillarity action.

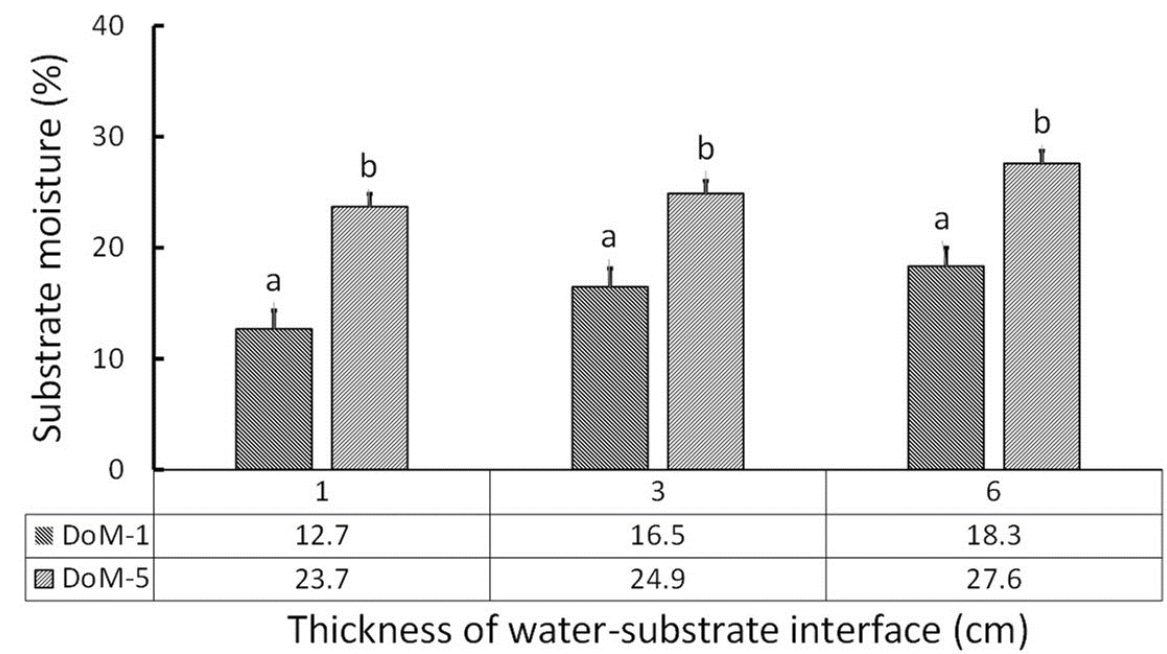

Figure 1 Substrate moisture measured at depths of $1 \mathrm{~cm}$ (DoM-1) and $5 \mathrm{~cm}$ (DoM-5) below substrate surface in different thicknesses of water-substrate interface. Different letters on top of bars indicate a significant difference between depths of measurements in each WSI treatment.

Depth and range of soil moisture measurements are varied depending on the objective of the study and characteristics of a soil profile. Gao et al. [18] measured soil moisture to a depth of $160 \mathrm{~cm}$ with 20 $\mathrm{cm}$ intervals in their study on soil moisture variability along transects over a well-developed gully. Cheng [19] et al. measured to a $200 \mathrm{~cm}$ depth but at $40 \mathrm{~cm}$ intervals plus additional measurements at $20 \mathrm{~cm}$ depth in their study on required precipitation intensities for reaching depths of $200 \mathrm{~cm}$. Zhu and Lin [20] specifically measured at depths of 10,40 , and $80 \mathrm{~cm}$ as representations of top, near-top, and sub soils in 
their study on influences of soil, terrain, and crop growth on soil moisture variation. Meanwhile, Kader et al. [21] measured at depths of 5,15 , and $25 \mathrm{~cm}$ in their study on soybean under rain-fed condition. High variability in the depths of soil moisture measurements chosen by researchers in agricultural research is related to expected water distribution throughout soil horizon and/or root distribution within the rhizosphere of the studied crop.

In floating culture system, the bottom part of the substrate within the pot is set to have direct contact with water surface. This contact can be achieved by setting the total weight of all substrate-filled pots loaded on the floating raft that exceeds maximum load capacity, such that the raft is completely submerged in water at the desired depth. The base of substrate submerged in water within the pot is called the water-substrate interface, abbreviated to WSI [10].

The source of water for supporting plant growth and development is mainly provided from water underneath the pots, penetrating each pot through 4 bottom holes. Soon after direct contact between the water and the growing substrate, an upward transfer of water to the upper surface of the substrate is driven by capillarity force $[22,23]$. Measurement of substrate moisture at depths of 1 and $5 \mathrm{~cm}$ in this study was designed to ensure that water was successfully transported from the bottom to the upper part of the substrate. Therefore, additional watering was not needed.

Celery growth under different depths of water-substrate interface

Steady growth of celery plants was observed in all treatments during the $3^{\text {rd }}$ and $4^{\text {th }}$ weeks. However, there were significantly different growth rates amongst plants treated with different depths of water-substrate interface. The fastest growth was exhibited by plants grown on the floating raft with the thinnest WSI (Figure 2). However, the effects of WSI on the number of leaves in 7 consecutive measurements from 14 DAT to 45 DAT were mostly not significant or inconsistent. Meanwhile, NPK fertilizer at the rate of $15 \mathrm{~g} / \mathrm{plant}$ exhibited a higher number of leaves compared to the application at lower rates, i.e., 5 and $10 \mathrm{~g} /$ plant (Figure 3).

In floating culture system used in this study, substrate thickness in all pots was similar. Therefore, positive effects of thin WSI, specifically on plant height and generally on growth, may not be directly due to the thinness of the WSI itself, but more likely due to the larger volume of aerobic substrate. Reversely, thicker WSI causes a smaller volume of aerobic substrate. Although wild celery plant was reported originally to be from marsh ecosystem [24], cultivated celery has fine roots without aerenchyma space, as typically found in roots of wetland plants. A small volume of aerobic substrate restricts root growth and development. In turn, it also restricts the growth of above ground organs [25].

Restriction on root growth did not affect the development of new leaves in this study; as a result, the number of leaves was not significantly different amongst WSI treatments ranging from 1 to $6 \mathrm{~cm}$ depth. Leaf development involves initiation, determination, transition, expansion, and maturation. Many genes and small RNAs have been known to be involved in leaf development [26]. Leaf development in celery seems to be genetically-controlled and not affected by restriction on root growth or development.

Although statistical analysis did not always assume significant differences amongst WSI treatments, WSI at a depth of $1 \mathrm{~cm}$ consistently exhibited higher leaf length $\times$ width, except in measurement at 14 DAT in plants fertilized with $15 \mathrm{~g} /$ plant (Figure 4). Leaf length $\times$ width had been used as a predictor in estimating leaf area in celery plant, and the coefficient for converting leaf length $\times$ width to leaf area in celery is 0.3431 , with accuracy of $87.24 \%$ [13]. A zero-intercept linear regression model [27] could be used for leaf area estimation in celery plants. 


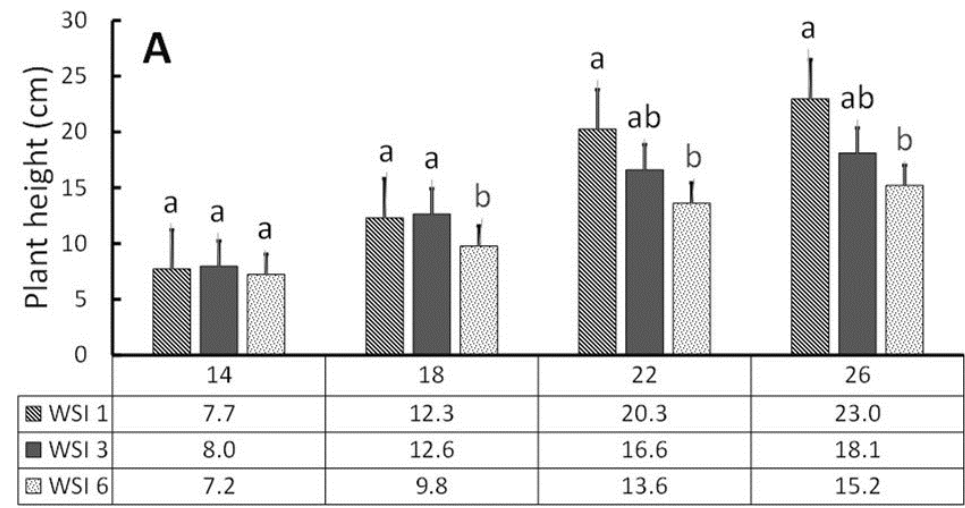

Days after transplanting
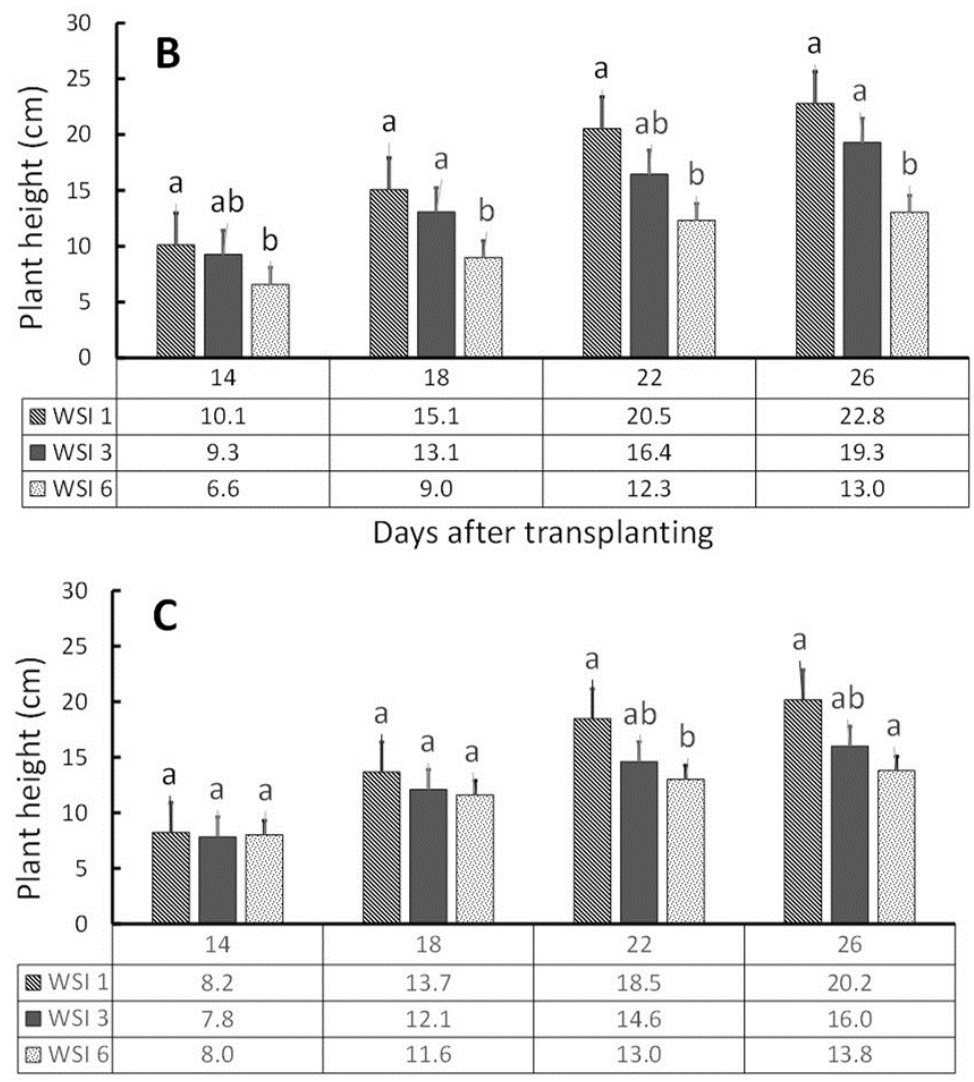

Days after transplanting

Figure 2 The thinnest water-substrate interface (WSI 1) exhibits the tallest leaf celery plants in each rate of NPK applications at $15 \mathrm{~g} /$ plant (A), $10 \mathrm{~g}$ /plant (B), and $5 \mathrm{~g} /$ plant (C), measured at 14, 18, 22, and 26 days after transplanting. Different letters on top of the bars at each day of measurement indicate significant differences amongst WSI treatments. 


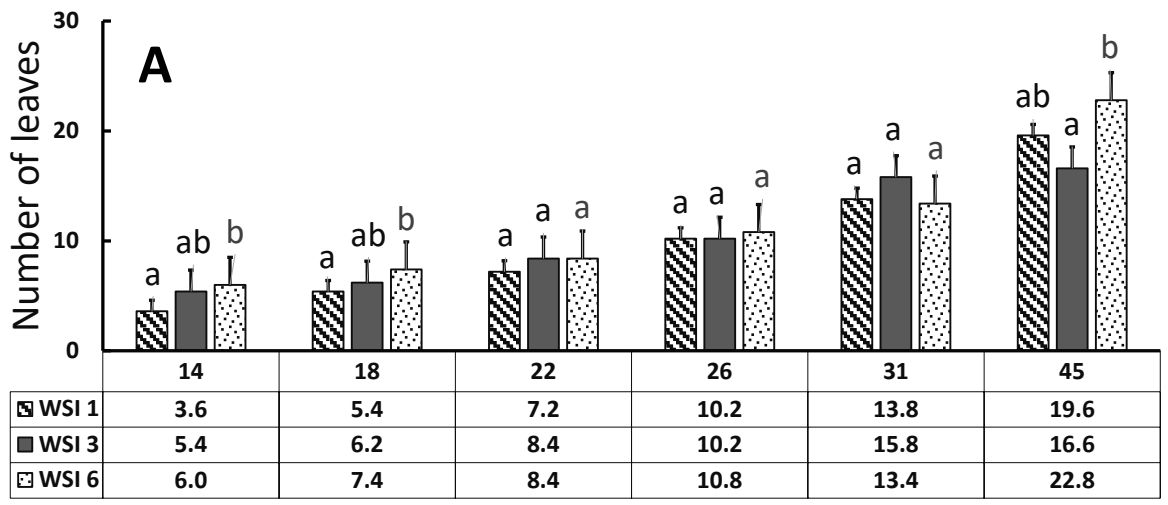

Days after transplanting

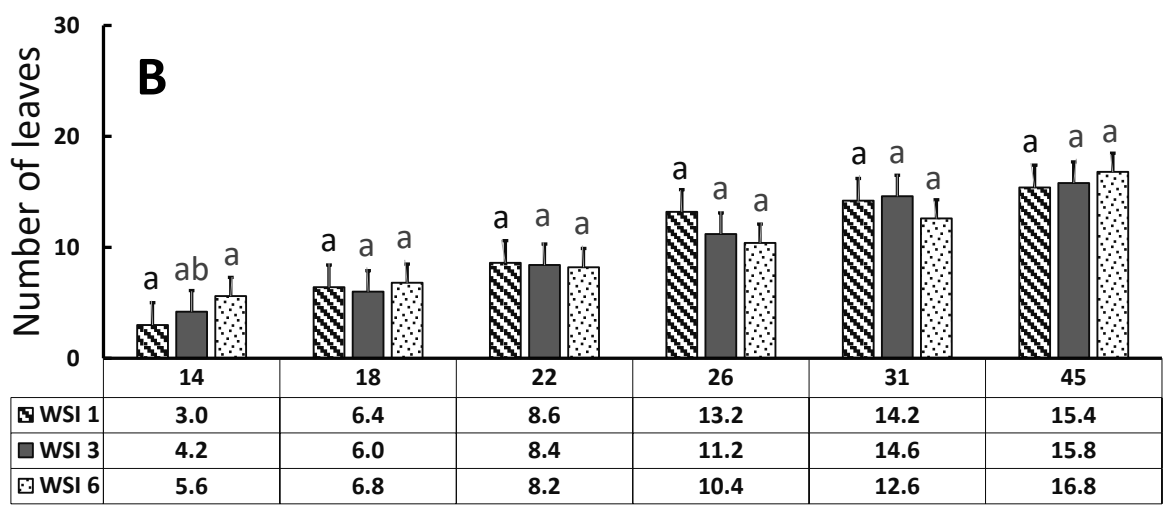

Days after transplanting

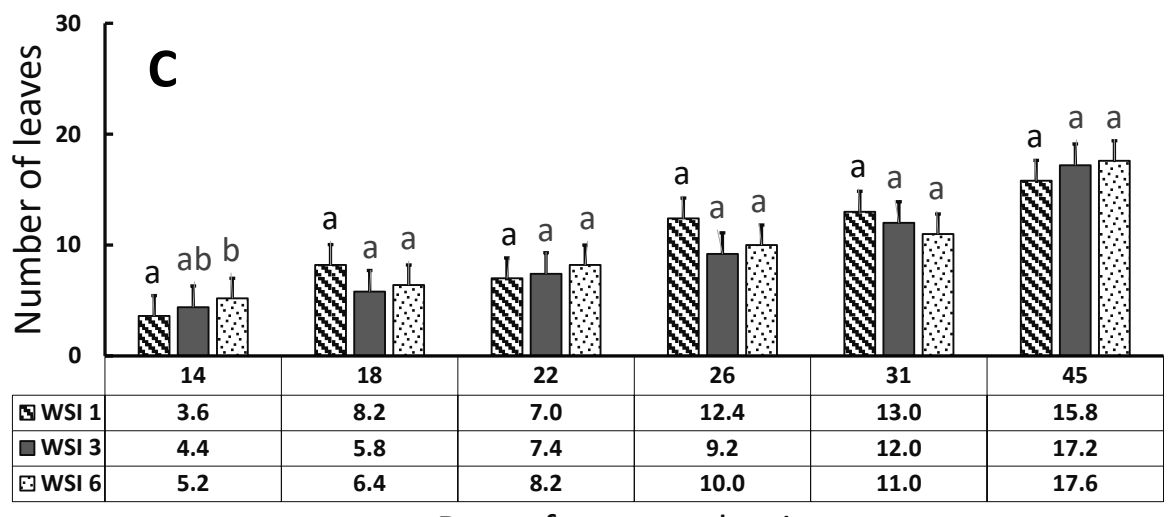

Days after transplanting

Figure 3 The number of leaves frequently counted from 14 to 45 days after transplanting in leaf celery plants grown using floating culture systems with different thicknesses of water-substate interface and rates of NPK application at $15 \mathrm{~g} /$ plant (A), $10 \mathrm{~g} / \mathrm{plant}(\mathbf{B})$, and $5 \mathrm{~g} /$ plant (C). Different letters on top of the bars at each day of measurement indicates significant differences amongst WSI treatments. 
http://wjst.wu.ac.th

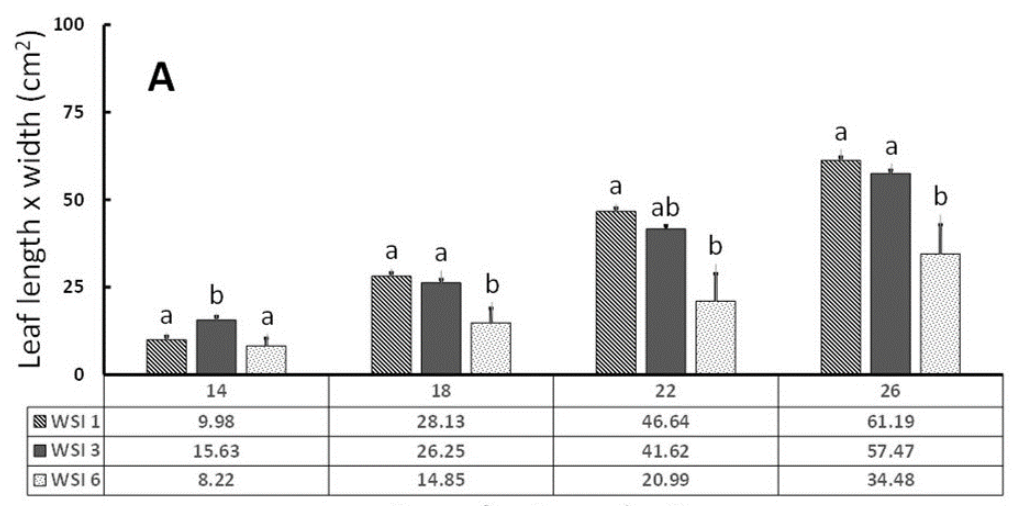

Days after transplanting

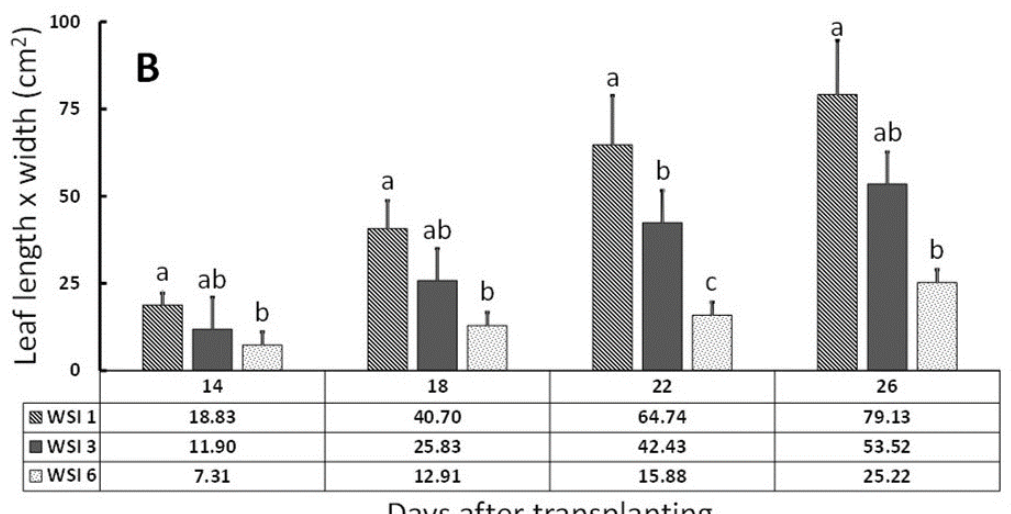

Days after transplanting

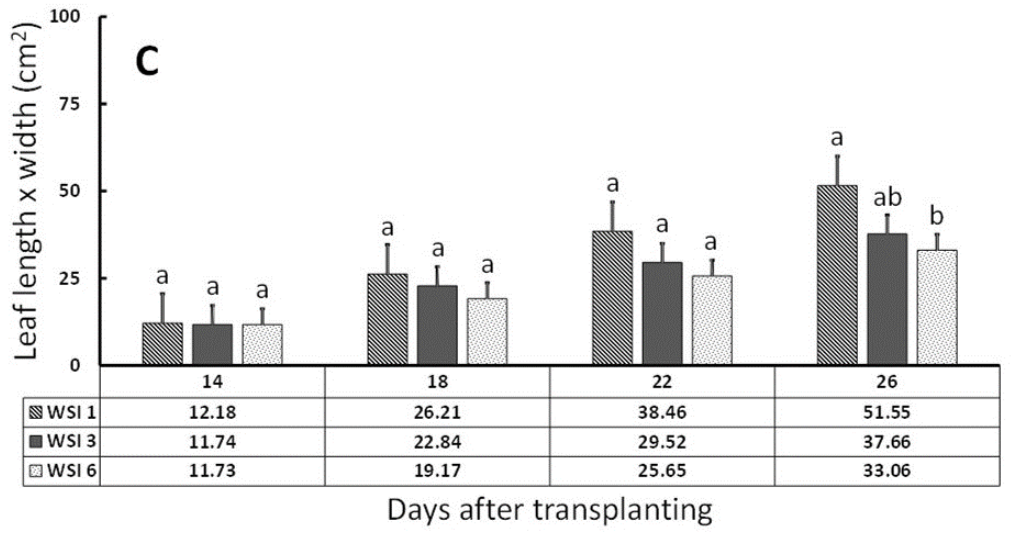

Figure 4 Length $\times$ width of the largest leaf was measured from 14 to 26 days after transplanting in celery plants grown using floating culture systems with different thicknesses of water-substate interface and rates of NPK application at $15 \mathrm{~g} /$ plant (A), $10 \mathrm{~g} / \mathrm{plant}(\mathbf{B})$, and $5 \mathrm{~g} /$ plant $(\mathbf{C})$. Different letters on top of the bars at each day of measurement indicate significant differences amongst WSI treatments. 


\section{Yield components in celery}

There are 3 types of cultivated celery. Golubkina et al. [2] used all 3 of these types in their study. The types are leaf, stalk, and root celeries. This study focused on leaf celery (A. graveolens). Leaf celery produces more compound leaves, consisting of 5 to 9 leaflets, but much smaller petiole compared to stalk celery, and produces much smaller corm compared to root celery. The harvested yield of leaf celery is its leaf, including the blade and petiole. Therefore, valuable yield components are the number of leaves and the yield fresh weight. There was an increasing trend in the number of harvested leaves and the yield fresh weight as NPK application rates were increased; however, significant upsurges were only observed in yield fresh weight if WSI was not deeper than $3 \mathrm{~cm}$ (Figure 5). Shoot dry weight followed the trend exhibited by yield fresh weight in the studied celery plant (Figure 6). These similar trends were predictable, since the most dominant part of the shoot in leaf celery are its leaves.

Ahmed et al. [28] reported that application with bio fertilizer plus inorganic NPK significantly increased vegetative growth characters, i.e., plant height and the fresh and dry weights of aerial parts in celery plants. However, the effects depended on agroclimatic conditions and the types of soil used. They suggested the need for more studies concerning the effect of NPK fertilizer and biofertilization on celery plants under different environments to reach the optimum combination to achieve the best yield. This suggestion related to our finding that the positive effect of NPK fertilizer on the yield fresh weight of celery plants cultivated using floating culture system was achieved if the depth of WSI was $3 \mathrm{~cm}$ or less.

Navarro et al. [29] discovered that the yield and size of marketable organs in celery plants were greater with inorganic fertilizer treatment; however, the nutritional quality of the celery plants was better in those plants treated with organic fertilizer. Tanwar et al. [30] also reported that biological amendments increased celery yield by increasing leafstalk length, the number of leafstalks, leaf area, and basal disc diameter. Moreover, amendment at the transplanting stage increased the production of high-quality celery stalks with better nutrition and a reduced need for inorganic fertilizer. Niu et al. [31] argued that application of $200 \mathrm{~kg} \mathrm{~N} / \mathrm{ha}$ in aerated irrigation systems effectively improved soil biological environments and increased $\mathrm{N}$ utilization rate. These mixed findings lead to the assumption that organic and inorganic fertilizers are needed in celery cultivation yet should be mixed in much different proportions based on agroclimatic conditions and cultivation practices. 
http://wjst.wu.ac.th


Figure 6 The cumulative shoot dry weight measured at selected days after transplanting in leaf celery plants fertilized with different rates of NPK application and thicknesses of water-substate interface of 1 $\mathrm{cm}(\mathbf{A}), 3 \mathrm{~cm}(\mathbf{B})$, and $6 \mathrm{~cm}(\mathbf{C})$.

\section{Yield components and early yield prediction}

The number of harvested leaves, fresh leaf yield, and shoot dry weight in leaf celery plants were interrelated, as proven in Figure 7. There was a strong correlation between the number of harvested leaves and fresh weight yield. Further, a strong correlation was also exhibited between fresh leaf yield and shoot dry weight. 
Based on a study using 29 varieties of celery, Shen et al. [32] concluded that celery yield exhibited significant positive correlations with some morphological traits, including individual plant quality, plant height, and petiole diameter. A strong correlation between morphological traits had also been reported in other crops. For instance, Janwar et al. [33] reported that a strong positive correlation between the number of bolls per plant, lint index, and staple length with cottonseed yield per plant. Bisen et al. [34] listed morphological traits which were significantly correlated with corn yield. The traits included grains per cob, grains per row, shelling percentage, grain rows per cob, cob per plant, harvest index, cob weight, cob girth, and seed index. Bagati et al. [35] also had recognized that some yield components exhibited significant positive genotypic and phenotypic correlations with grain yield in basmati rice. The yield components included tillering ability, spikelet fertility percentage, number of grains per panicle, and 1,000 -grain weight.
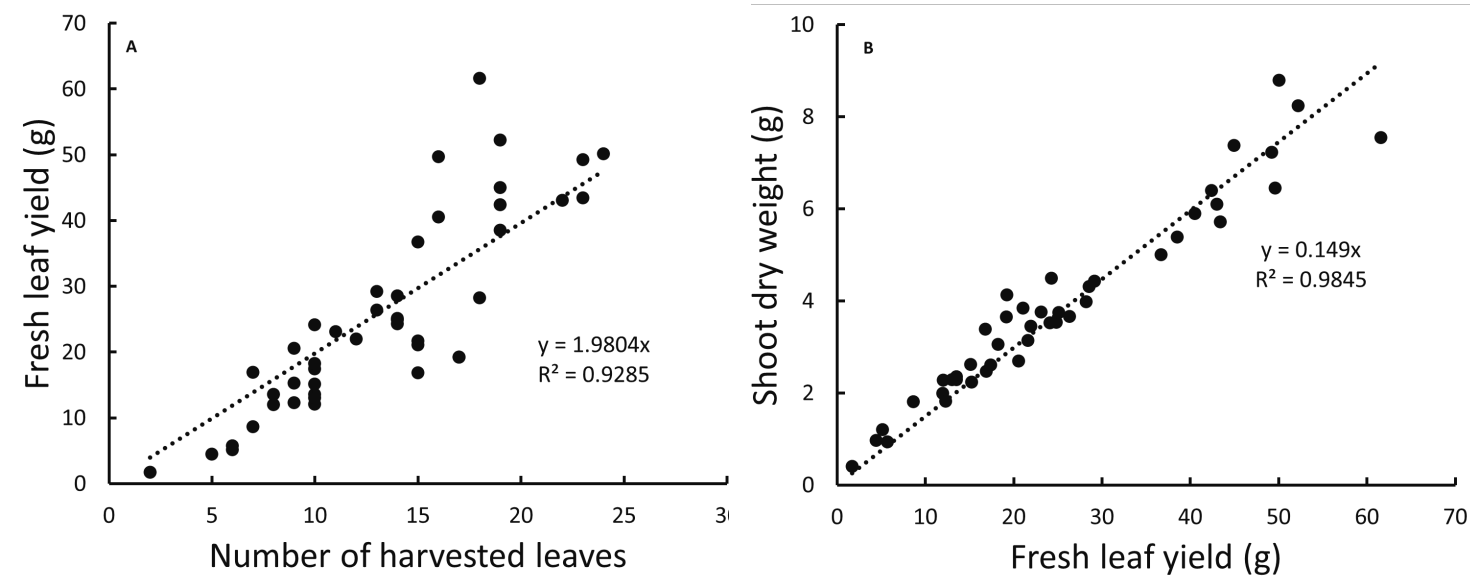

Figure 7 Interrelated amongst number of harvested leaves, fresh leaf yield, and shoot dry weight in leaf celery plants.

Some of the morphological traits can be used as reliable predictors for upcoming yield in many crops. The measurable traits at the earliest plant growth stage and exhibited reliable correlation with yield are the most advantageous predictors. Some early measurable morphological traits for predicting cumulative fresh yield in leaf celery are displayed in Figure 8.

The harvested yield of the celery plant is the leaves, consisting of the petiole and blade. Celery has a very short stem at the center of the plant, but has long petioles. The marketed part of celery is the whole shoot except for old and senescence leaves. Planting materials can be true seeds or young suckers, separated from mother plants, grown with or without roots. It takes a much longer time to harvest if true seeds are used as planting materials, due to the slow growth of celery at the seedling stage. Celery can be harvested at 45 days after transplanting (DAT) if young suckers are used as planting materials. Celery is harvested at the vegetative growth stage. Yield at harvest can be predicted as early as 26 DAT, based on plant height or the midrib length of the largest leaf. The ability to predict yield earlier is useful for farmers in planning their marketing strategies.

Early yield prediction using morphological traits has not been intensively studied. In contrast, morphological traits have been widely used in plant breeding for selecting desirable lines and developing new varieties, mostly for increasing yield. Maleki et al. [36] used correlation and sequential path analysis approaches for improving dry leaf yield in tobacco based on some agronomic traits, including fresh leaf yield, leaf length, leaf number, and stem circumference. Fellahi et al. [37] suggested using biological yield (biomass) and harvest index as quantitative traits in selecting bread wheat for higher grain yield. 
Mousavi et al. [38] reported that corn grain yield had a positive correlation with plant height, outer ear diameter, the weight of ear, the weight of cob, the number of leaves, total seeds weight per ear, the weight of 1,000 seeds, stem diameter, the number of seeds per column, and total fresh weight per hectare. Lopes et al. [39] concluded that agronomic and physiological traits were able to predict yield variation across 288 advanced spring wheat lines, especially under stressful environmental conditions. Meanwhile, Sandhu et al. [40] found that rice grain yield was significantly and positively correlated with seedlingestablishment traits, root morphological traits, nutrient uptake-related traits, and grain yield-contributing traits.
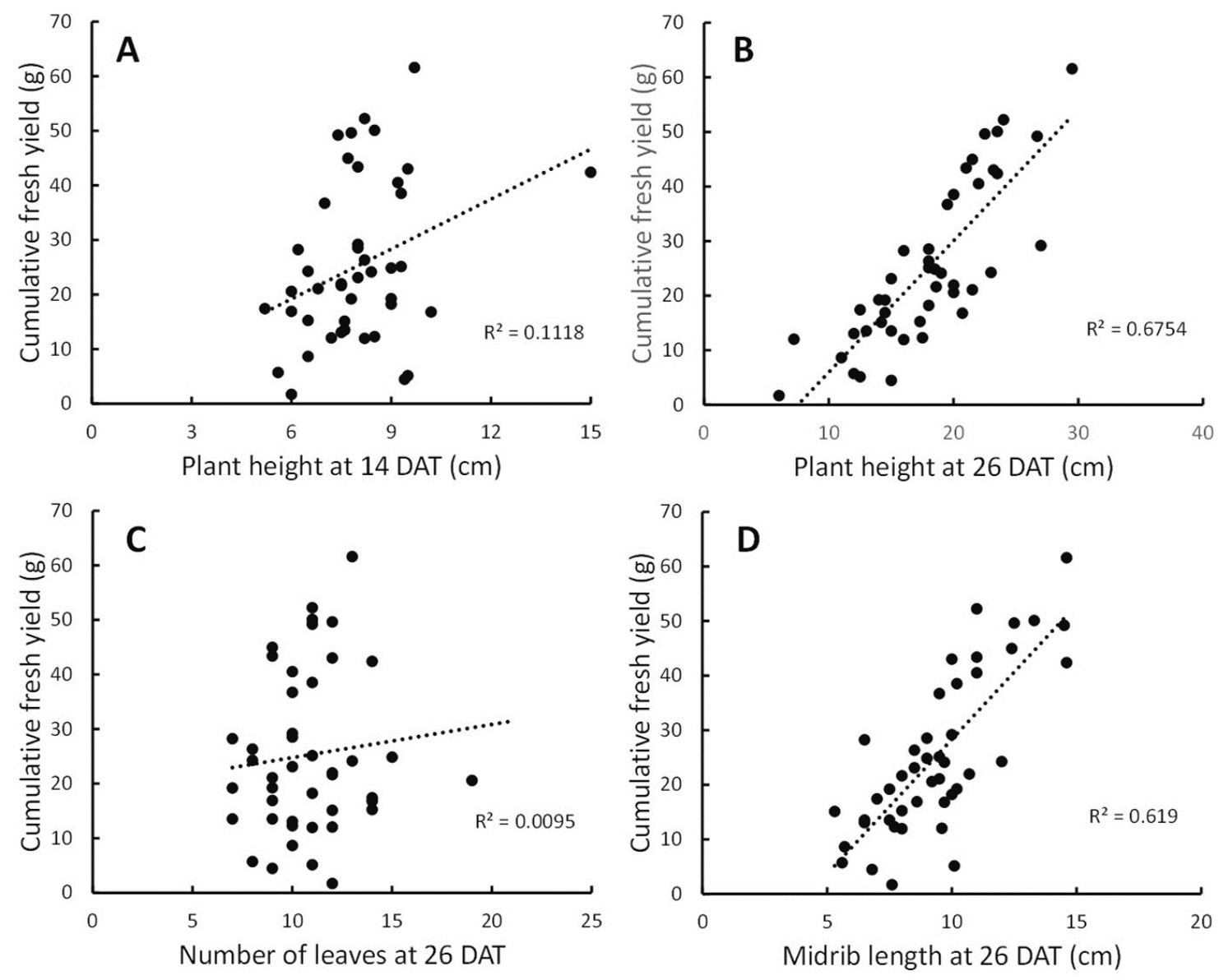

Figure 8 Plant height at 14 DAT (A), plant height at 26 DAT (B), number of leaves at 26 DAT $(\mathbf{C})$, and midrib length of the largest leaf at 26 DAT (D) used as measurable morphological traits for predicting cumulative fresh yield in leaf celery. 


\section{Conclusions}

Leaf celery can be cultivated using a floating culture system with the benefit of continuous water supply from the bottom of the growing substrate due to capillarity force. The bottom part of the substrate should be kept in direct contact with the water surface; however, depth of water-substrate interface (WSI) should be maintained at $3 \mathrm{~cm}$ or less. Otherwise, leaf celery response to NPK-fertilizer application was diminished, since deeper WSI directly limits the aerobic rhizosphere. There was interrelation between some morphological traits and fresh leaf yield. Furthermore, the midrib length of the largest leaf and plant height at 26 DAT can be used as a predictor of leaf celery yield, harvested at 45 DAT.

\section{Acknowledgements}

We would like to express our gratitude to the editorial team of this journal for their help and the unanimous reviewers for their comments and suggestions. This research was funded by the Applied Research Program, Ministry of Research and Technology, Indonesia, Grant No. 299/SP2H/LT/DRPM/2021.

\section{References}

[1] W Kooti and N Daraei. A review of the antioxidant activity of celery (Apium graveolens L). J. Evid. Based Complement. Altern. Med. 2017; 22, 1029-34.

[2] NA Golubkina, VA Kharchenko, AI Moldovan, AA Koshevarov, D Zamana, S Nadezhkin, A Soldatenko, A Sekara, A Tallarita and G Caruso. Yield, growth, quality, biochemical characteristics and elemental composition of plant parts of celery leafy, stalk and root types grown in the Northern Hemisphere. Plants 2020; 9, 484.

[3] M Li, X Hou, F Wang, G Tan, Z Xu and A Xong. Advances in the research of celery, an important Apiaceae vegetable crop. Cr. Rev. Biotech. 2018; 38, 172-83.

[4] AK Yommi NN Di Gerónimo, LE Carrozzi, V Quillehauquy, M Goñi and SI Roura. Morphological, physicochemical and sensory evaluation of celery harvested from early to late maturity. Hort. Brasileira 2013; 31, 236-41.

[5] O Leroux. Collenchyma: A versatile mechanical tissue with dynamic cell walls. Ann. Bot. 2012; 110, 1083-98.

[6] D Chen, LD Melton, Z Zujovic and VJ Harris. Developmental changes in collenchyma cell-wall polysaccharides in celery (Apium graveolens L.) petioles. BMC Plant Biol. 2019; 19, 81.

[7] AA Helaly, An El-Refy, E Mady, AK Mosa and L Craker. Morphological and molecular analysis of three celery accessions. J. Med. Act. Plant. 2014; 2, 3-4.

[8] B Lakitan, E Siaga, K Kartika and Y Yunindyawati. Use of Scleria poaeformis as biomaterial in etnoagricultural practice at riparian wetlands in Indonesia. Bulg. J. Agric. Sci. 2019; 25, 320-5.

[9] RB Chowdhury and GA Moore. Floating agriculture: A potential cleaner production technique for climate change adaptation and sustainable community development in Bangladesh. J. Clean. Prod. $2015 ; \mathbf{1 5 0}, 371-89$

[10] KK Jaya, B Lakitan and ZP Negara. Depth of water-substrate interface in floating culture and nutrient-enriched substrate effects on green apple eggplant. Agrivita J. Agric. Sci. 2019; 41, 230-7.

[11] E Siaga, B Lakitan, SM Bernas, A Wijaya, R Lisda, F Ramadhani and M Meihana. Application of floating culture system in chili pepper (Capsicum annum L.) during prolonged flooding period at riparian wetland in Indonesia. Aust. J. Crop Sci. 2018: 12, 808-16.

[12] SM Bernas, A Pohan, SNA Fitri and E Kurniawan. Bamboo floated-cultivation model for upland kangkong (Ipomoea reptans Poir.) in tidal lowland area. J. Lahan Sub-optim. 2012; 1, 177-85.

[13] B Lakitan, K Kartika, S Susilawati and A. Wijaya. Acclimating leaf celery plant (Apium graveolens) via bottom wet culture for increasing its adaptability to tropical riparian wetland ecosystem. Biodivers. J. Biol. Divers. 2021; 22, 320-8.

[14] V Toorn. Methods to improve celery (Apium Graveolens L.) seed quality. Acta Hort. 1990; 267, 175-82. 
[15] K Weitbrecht, K Müller and G Leubner-Metzger. First off, the mark: Early seed germination. $J$. Exp. Bot. 2011; 62, 3289-309.

[16] B Lakitan and E Siaga. 2019, Floating raft constructed using used plastic bottle for rice seedling preparation. Granted Patent IDP000065141.

[17] L Dinca, O Badea, G Guiman, C Braga, V Crisan, V Greavu, G Murariu, and L Georgescu. Monitoring of soil moisture in long-term ecological research (LTER) sites of Romanian Carpathians. Ann. For. Res. 2018; 61, 171-88.

[18] X Gao, P Wu, X Zhao, Y Shi, J Wang and B Zhang. Soil moisture variability along transects over a well-developed gully in the Loess Plateau, China. Catena 2011; 87, 357-67.

[19] Y Cheng, W Yang, H Zhan, Q Jiang, M Shi, Y Wang, X Li and Z Xin. On change of soil moisture distribution with vegetation reconstruction in $\mathrm{Mu}$ Us sandy land of China with newly designed lysimeter. Front. Plant Sci. 2021; 12, 609529.

[20] Q Zhu and H Lin. Influences of soil, terrain, and crop growth on soil moisture variation from transect to farm scales. Geoderma 2011; 163, 45-54.

[21] MA Kader, M Senge, MA Mojid and K Nakamura. Mulching type-induced soil moisture and temperature regimes and water use efficiency of soybean under rain-fed condition in central Japan. Int. Soil Water Conserv. Res. 2017; 5, 302-8.

[22] U Burbaum and I Sass. Physics of adhesion of soils to solid surfaces. Bull. Eng. Geol. Environ. 2017; 76, 1097-105.

[23] C Hulin and L Mercury. Capillarity-driven supersolubility in dual-porosity systems. Geochim. Cosmochim. Acta 2019; 252, 1-268.

[24] F Megaloudi. Wild and cultivated vegetables, herbs and spices in Greek antiquity (900 BC to 400 BC). Environ. Archaeol. 2005; 10, 73-82.

[25] T Colombi, LC Torres, A Walter and T Keller. Feedbacks between soil penetration resistance, root architecture and water uptake limit water accessibility and crop growth: A vicious circle. Sci. Total Environ. 2018; 626, 1026-35.

[26] T Yang, Y Wang, S Teotia, Z Zhang and G Tang. The making of leaves: How small RNA networks modulate leaf development. Front. Plant Sci. 2018; 9, 824.

[27] B Lakitan, LI Widuri and M Meihana. Simplifying procedure for a non-destructive, inexpensive, yet accurate trifoliate leaf area estimation in snap bean (Phaseolus vulgaris). J. Appl. Hort. 2017; 19, 1521.

[28] ZA Ahmed. Effect of NPK and bio fertilization on growth and oil yield of celery (Apium graveolens L.) and dill (Anethum graveolens L.) plants. J. Plant Prod. 2017; 8, 247-51.

[29] AS Navarro, JAS Romero, MDCS Sanjuan, MAB Bernardeau and MJD Iniesta. Medium-term influence of organic fertilization on the quality and yield of a celery crop. Agronomy 2020; 10, 1418A.

[30] Tanwar, K Yadav, K Prasad and A Aggarwal. Biological amendments on growth, nutritional quality, and yield of celery. Int. J. Veg. Sci. 2013; 19, 228-39.

[31] W Niu, Q Zhang, B Cui, X Gu, L Guo, and B Liang. Effects of nitrogen on soil microbial abundance, enzyme activity, and nitrogen use efficiency in greenhouse celery under aerated irrigation. Soil Sci. Soc. Amer. J. 2018; 82, 606-13.

[32] D Shen, L Chen, X Lu, J Tao, G Feng, J Liu, K Feng, L Yin, X Ding, L Jia, Z Xu, H Liu and A Xiong. Resources evaluation of 29 celery varieties for autumn-winter cultivation in southern Jiangsu. Acta Agric. Zhejiangensis 2020; 32, 653-60.

[33] AH Jarwar, X Wang, MS Iqbal, Z Sarfraz, L Wang, Q Ma and F Shuli. Genetic divergence on the basis of principal component, correlation and cluster analysis of yield and quality traits in cotton cultivars. Pak. J. Bot. 2019; 51, 1-6.

[34] N Bisen, CP Rahangdale and RP Sahu. Genetic variability and correlation studies of yield and yield component in maize hybrids (Zea mays L.) under Kymore Plateau and Satpura Hill Region of Madhya Pradesh. Int. J. Agric. Environ. Biotech. 2018; 11, 71-7. 
[35] S Bagati, AK Singh, RK Salgotra, R Bhardwaj, M Sharma, SK Rai, and A Bhat. Genetic variability, heritability and correlation coefficients of yield and its component traits in basmati rice (Oryza sativa L.). SABRAO J. Breed. Genet. 2016; 48, 445-52.

[36] HH Maleki, G Karimzadeh, R Darvishzadeh and A Sarrafi. Correlation and sequential path analysis of some agronomic traits in tobacco (Nicotiana tabacum L.) to improve dry leaf yield. Aust. J. Crop Sci. 2011: 5, 1644-8.

[37] Z Fellahi, A Hannachi, H Bouzerzour, and A Boutekrabt. Correlation between traits and path analysis coefficient for grain yield and other quantitative traits in bread wheat under semiarid conditions. J. Agric. Sustain. 2013; 3, 16-26.

[38] SMN Mousavi and J Nagy. Evaluation of plant characteristics related to grain yield of FAO410 and FAO340 hybrids using regression models. Cereal Res. Commun. 2021; 49, 161-9.

[39] MS Lopes, MP Reynolds, MR Jalal-Kamali, M Moussa, Y Feltaous, ISA Tahir, N Barmae, M Vargasa, Y Mannes and M Baum. The yield correlations of selectable physiological traits in a population of advanced spring wheat lines grown in warm and drought environments. Field Crop. Res. 2012; 128, 129-36.

[40] N Sandhu, SR Subedi, VK Singh, P Sinha, S Kumar, SP Singh, SK Ghimire, M Pandey, RB Yadaw, RK Varshney and A Kumar. Deciphering the genetic basis of root morphology, nutrient uptake, yield, and yield-related traits in rice under dry direct-seeded cultivation systems. Sci. Rep. 2019; 9, 9334. 